\title{
Correction to: Composition of unfermented, unroasted, roasted cocoa beans and cocoa shells from Peninsular Malaysia
}

\author{
Baizura Aya Putri Agus ${ }^{1} \cdot$ Nurul Nadzirah Mohamad $^{1} \cdot$ Norhayati Hussain $^{1,2}$
}

Published online: 14 September 2018

○) Springer Science+Business Media, LLC, part of Springer Nature 2018

\section{Correction to: \\ Journal of Food Measurement and Characterization https://doi.org/10.1007/s11694-018-9875-4}

The original version of this article unfortunately contained an error in Fig. 1. Corrected version of Fig. 1 is given below.

In Results and Discussion, Fat Content subsection, the sentence "Fat content of unroasted cocoa beans $(42.65 \%)$ was significantly $(\mathrm{p}<0.05)$ higher compared to roasted cocoa beans (30.00\%), unroasted cocoa shells $(4.87 \%)$, roasted cocoa shells $(3.09 \%)$ and unfermented cocoa beans $(0.32 \%)$." should read as below:

Fat content of unroasted cocoa beans (42.65\%) was significantly ( $\mathrm{p}<0.05$ ) higher compared to unfermented cocoa beans $(41.51 \%)$, roasted cocoa beans $(30.00 \%)$, unroasted cocoa shells $(4.87 \%)$ and roasted cocoa shells (3.09\%).
Fig. 1 Fat content of Peninsular Malaysia unfermented, unroasted, roasted cocoa beans and cocoa shells. Values are expressed as mean \pm standard deviation $(n=4)$. Means with different letters were significantly different at level of $\mathrm{p}<0.05$

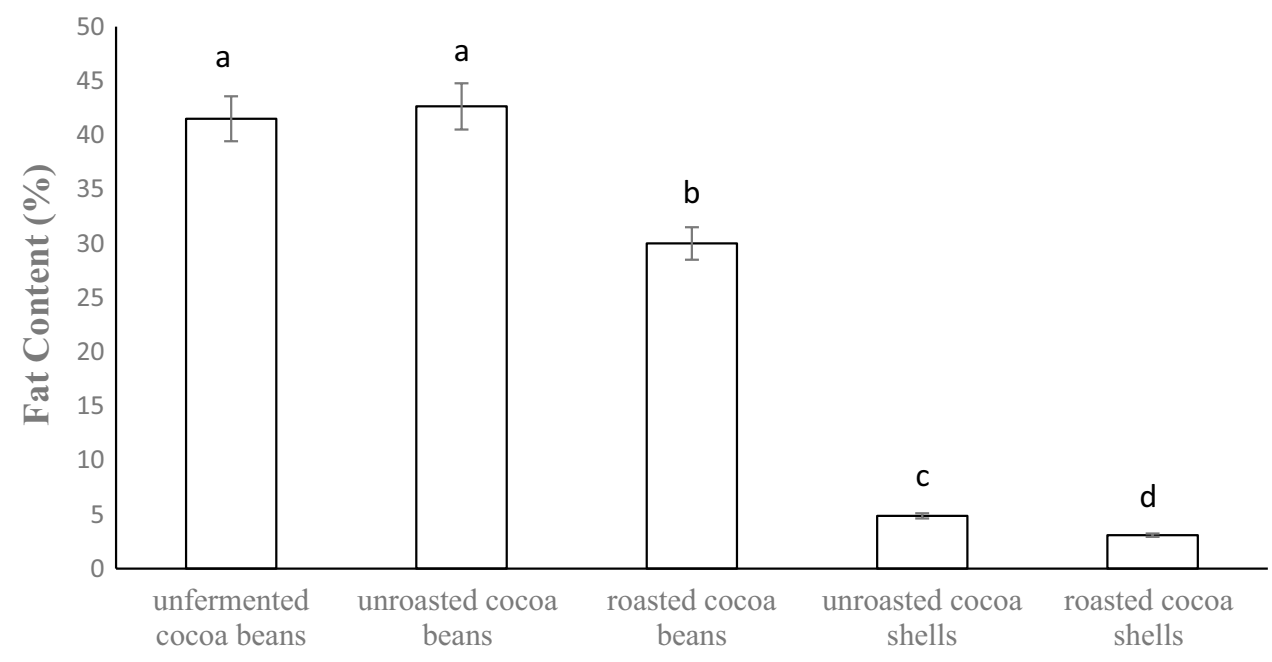

Stages of processed cocoa beans

The original article can be found online at https://doi.org/10.1007/ s11694-018-9875-4.

Norhayati Hussain

aryatihussain@upm.edu.my

1 Department of Food Technology, Faculty of Food Science and Technology, Universiti Putra Malaysia, Serdang, Selangor, Malaysia

2 Halal Products Research Institute, Universiti Putra Malaysia, Putra Infoport, 43400 Serdang, Selangor, Malaysia 